\title{
Safety of $\boldsymbol{\beta 2}$-Agonists in Asthma: Linking Mechanisms, Meta-Analyses and Regulatory Practice
}

\author{
Sanjeeva. B. Dissanayake $e^{1,2}$
}

\begin{abstract}
Received 3 November 2014; accepted 3 February 2015; published online 25 February 2015
Abstract. An epidemic of asthma fatalities in the 1970s prompted a series of case-control studies which indicated that short acting $\beta$-agonists increased the risk of death. Subsequent mechanistic and pharmacodynamic studies have suggested that $\beta$-agonist monotherapy facilitates airway inflammation, although when co-administered with inhaled corticosteroids (ICSs), similar evidence is lacking. The Salmeterol Multicenter Asthma Research Trial, which revealed a fourfold increase in asthma-related deaths in salmeterol-treated patients, prompted a paradigm shift in the evidential assessment of $\beta$-agonist safety. The FDA's meta-analysis of over 60,000 patients ultimately concluded that long-acting $\beta$-agonist (LABA) therapy increased the risk of serious asthma-related events. However, this meta-analysis itself raised questions given a large body of omitted data and a limited emphasis on the risk of ICS-LABA coadministration. Subsequently, the FDA mandated the conduct of five large studies to definitively ascertain whether ICS-LABAs increase asthma-related risk. Whether this ambitious programme will provide certainty remains to be seen given issues of multiplicity, the very low frequency of fatal and nearfatal asthma, and the administration of a free combination of ICS and LABA in one trial. The FDA's de facto use of FEV1 as a safety parameter, based on findings from the Foradil NDA, is a further topical issue: subsequent clinical study data, considerations relating to regional pulmonary drug deposition and pharmacological differences between different $\beta$-agonists suggest that FEV1 may be a suboptimal safety metric. Models evaluating airway inflammation and bronchial reactivity may be more appropriate to assess the relative risk of asthma-related events.
\end{abstract}

KEY WORDS: FDA; FEV1; long-acting $\beta$-agonists; meta-analyses; safety.

\section{INTRODUCTION}

This paper relates to a presentation on $\beta$-agonist safety given at the "Orlando Inhalation Conference-Approaches in International Regulation" in March 2014. The presentation provided an overview of major events in the ongoing $\beta$-agonist safety debate and examined the relationship between mechanistic findings and clinical trial data. The FDA's LABA safety meta-analysis, the post-market safety studies mandated by FDA, and the use of FEV1 as a de facto safety metric were also discussed.

\section{MAIN TEXT}

An increase in asthma mortality was reported in England and Wales $(1,2)$, Australia and New Zealand (2) in the mid1960s. No adequate studies were undertaken to identify a

\footnotetext{
${ }^{1}$ Respiratory Medical Sciences, Mundipharma Research Limited, Cambridge Science Park, Milton Road, Cambridge, CB4 0G, UK.

${ }^{2}$ To whom correspondence should be addressed. (e-mail: sanjeeva.dissanayake@mundipharma-rd.eu)
}

cause for this trend. However, the (over)use of $\beta$-agonists was circumstantially implicated by the temporal association between increasing sales and an increase in asthma-related death, followed by a reduction in mortality once warnings as to the potential role of these drugs were disseminated $(1,3)$. A second epidemic of asthma deaths in New Zealand, commencing the year after the local launch of fenoterol and reaching an unprecedented peak of 4.1 asthma deaths per 100,000 per annum amongst those aged 5 to 34 years in 1979 (4), prompted a series of case-control studies which indicated that excessive use of fenoterol (5-7), and to a lesser extent salbutamol (8) (albuterol), increased the risk of asthma death. Several authors subsequently examined how $\beta$-agonists might lead to increased asthma mortality, if not via delaying presentation for appropriate medical care. In the absence of concomitant inhaled corticosteroids (ICS), a variety of potentially deleterious mechanistic effects of $\beta-2$ agonists were shown, albeit not invariably so. A near-doubling in sputum eosinophil levels (9), an increase in airways hyperresponsiveness (AHR) to both direct (10) and indirect (9) stimuli and an increase in the allergen-induced late asthmatic response (11) and allergen-induced AHR (11) have all been reported with regular $\beta$-agonist monotherapy. It has been suggested that the precursor to these effects may be an 
adverse $\beta$-agonist-induced shift in the Th1/Th2 cytokine milieu (12-14). When $\beta$-agonists are used in conjunction with inhaled corticosteroids, mechanistic data suggestive of an increased risk are, however, less compelling. Although some authors have reported lesser bronchoprotection to AMP (9) or allergen challenge (11) with combination ICS and $\beta$ agonist than with ICS monotherapy, others have reported similar bronchoprotective effects with these treatments (15) whilst in most cases, bronchoprotection with regular combination therapy remains at clinically relevant level $(15,16)$. There is also little evidence of inflammatory cellular change with combination therapy $(9,15)$.

The seminal Salmeterol Multicenter Asthma Research Trial (SMART) which reported a fourfold increase in asthma mortality in patients randomised to salmeterol versus placebo (17) led to a shift in focus in the $\beta$-agonist debate, towards much larger datasets and serious event-based outcomes, and prompted the Food and Drug Administration (FDA) to request comprehensive pooled safety analyses from manufacturers of LABAs for further evaluation. The FDA's reanalysis of these Sponsor data (from approximately 61,000 subjects) determined that the risk of a serious asthma-related event (i.e., death, intubation or hospitalisation) was significantly increased in subjects receiving versus not receiving LABA (risk difference 2.80 per 1000 subjects) (18). Although many of the FDA's secondary analyses supported its overall conclusion, a number of important issues received little prominence in the FDA's review. Firstly, approximately 95\% of the data provided by AstraZeneca appear to have been omitted from the FDA's meta-analysis. The grounds for exclusion of these data are not clear, although the use of the Turbohaler device in many AstraZeneca trials may be implicated since this inhaler device is not approved in the USA. Given the extent of the AstraZeneca database (approximately 24,000 subjects) and the fact that AstraZeneca's analyses showed no increase in risk of serious asthma-related events with formoterol (19), the almost complete omission of these data from the FDA analysis was potentially critical. Secondly, the FDA's analysis demonstrated that where patients were randomised to LABA and ICS combination therapy, there was no increase in risk versus ICS monotherapy (risk difference 0.25 per 1000 subjects). Unfortunately, these data (based on approximately 15,000 patients) constituted only one quarter of the total FDA dataset and were thus subsumed by the much greater volume of data in subjects not specifically assigned ICS alongside their LABA study treatment. A third key finding was that no asthmarelated deaths or intubations occurred in subjects treated with Advair or Symbicort; the only products included in the FDA review with which co-administration of ICS and LABA was assured (18).

The FDA has subsequently mandated that four manufacturers of LABA-containing products undertake five large-scale safety studies (four adult/adolescent, one paediatric_see Table I). In each trial, 11,700 asthmatics (6200 in the paediatric trial) with a history of exacerbations will be randomised to 6-month treatment with either ICS-LABA or ICS monotherapy at a fixed dose (20).

Whether this extensive programme of studies will provide definitive resolution remains uncertain (26). If 7 deaths are seen with ICS-LABA versus 1 with ICS in the
Table I. FDA-mandated LABA Safety Trials

\begin{tabular}{|c|c|c|c|c|c|}
\hline \multirow{2}{*}{$\frac{\text { Trial }}{1(21)}$} & \multicolumn{3}{|c|}{ Treatment arms } & \multirow{2}{*}{$\frac{\text { Age group }}{\geq 12 \text { years }}$} & \multirow{2}{*}{$\frac{\text { Sample size }}{11,700}$} \\
\hline & Advair & $v s$ & Flovent & & \\
\hline $2(22)$ & Symbicort & $v s$ & Pulmicort & $\geq 12$ years & 11,700 \\
\hline $3(23)$ & Dulera & $v s$ & Asmanex & $\geq 12$ years & 11,700 \\
\hline $4(24)$ & $\begin{array}{r}\text { Foradil + } \\
\text { Flovent }\end{array}$ & $v s$ & Flovent & $\geq 12$ years & 11,700 \\
\hline $5(25)$ & Advair & $v s$ & Flovent & $4-<12$ years & 6200 \\
\hline
\end{tabular}

46,800 patients enrolled across these trials (a plausible if pessimistic estimate) that will still fail to exclude the possibility that the true difference is zero since the $95 \%$ confidence interval will straddle unity (relative risk 7.0; $95 \%$ confidence interval (CI), 0.9-56.9) (26). Additionally, whilst each individual study is appropriately $(90 \%)$ powered, across five separately assessed, essentially replicate studies, the risk of failing to exclude a difference where none exists in at least one study, thereby wrongly deeming one treatment 'unsafe', is $41 \%\left(1-0.9^{4}\right)(26)$. The comparison of a combination of formoterol (Foradil DPI) and fluticasone via separate inhalers to fluticasone monotherapy in one trial is also of concern: GSK's salmeterol meta-analysis revealed a monotonic trend whereby the relative risk of serious asthmarelated events increased from fixed combination Advair (no increase in risk versus ICS monotherapy) to salmeterol plus ICS as randomised study treatment via separate inhalers to salmeterol added to background (non-study treatment) ICS (a definite increase in risk versus ICS monotherapy) (27). This trend is most plausibly explained by incomplete ICS adherence when non-single inhaler combinations are used, illustrating an important potential confounding influence in the Foradil trial.

An unresolved and intriguing question is whether all LABAs confer the same risk. When effects upon asthmarelated hospitalisation were assessed in the GSK and AZ meta-analyses, Advair had a neutral effect on risk versus fluticasone monotherapy (27), whereas formoterol plus budesonide (as single or separate inhalers) reduced the odds of hospitalisation by $32 \%$ versus budesonide monotherapy (19). Data from the FDA-mandated studies (summarised in Table I) may elucidate whether this difference is real.

A further issue is that of dose-related safety. A possible dose-related safety signal was seen in the Foradil New Drug Application (NDA) clinical programme $(28,29)$ with $2.0 \%$ versus $4.5 \%$ serious asthma exacerbations with Foradil $12 \mu \mathrm{g}$ versus $24 \mu \mathrm{g}$, respectively. The FDA has cited these data during subsequent NDA reviews $(30,31)$ as a basis for its 'lowest effective dose' philosophy. Interestingly, in a large Foradil phase IV study, conducted in response to the Foradil NDA data, there was no evidence of a dose-related safety signal (32). AstraZeneca's subsequent formoterol metaanalysis also showed no elevation in the risk of asthmarelated hospitalisation across regular formoterol (metered) daily doses up to $48 \mu \mathrm{g}$ or with adjustable maintenance dosing (19). The totality of these data query the regulatory use of FEV1 with established LABAs to define 'safe' doses of novel LABAs $(30,31)$, an approach seemingly based on the observation that Foradil $24 \mu \mathrm{g}$ demonstrated greater 
bronchodilation than $12 \mu \mathrm{g}$ in the NDA studies in which a putative dose-related safety signal was seen $(30,31)$.

The notion that safe doses of new LABAs should be identified by closely matching the bronchodilation attained with existing, approved products is further challenged by pharmacological considerations, and the relationship between pulmonary deposition pattern and clinical effect. Greater bronchodilatory effect (FEV1) has been attained with a large particle salbutamol monodisperse formulation exhibiting a more central deposition pattern despite a relatively lower total pulmonary dose than a small particle monodisperse formulation with a more peripheral deposition pattern (33) - implying that the larger particle formulation is both more efficacious and safer. With respect to pharmacological characteristics of inhaled LABAs (near)complete agonists, such as formoterol or indacaterol, occupy fewer receptors than partial agonists, such as salmeterol, to elicit a given smooth muscle relaxant effect. Thus, with the use of a complete agonist, more 'spare' receptors are available which can subsequently be bound and further relax smooth muscle. The maximal bronchodilatory effect that a partial agonist may generate is thus less than a complete agonist (34). Differences in $\beta 1 / \beta 2$ selectivity are also relevant. For example, in a rhesus monkey model at doses conferring similar (formoterol) or lesser (salmeterol) bronchoprotection versus indacaterol, both formoterol and salmeterol had greater and substantially more prolonged effects upon heart rate than indacaterol (35). These data imply that indacaterol may be dosed closer to its Emax, at least from a cardiovascular safety perspective, than salmeterol or formoterol allow. Overall, these pharmacological nuances illustrate the limitations of applying FEV1, a unidimensional efficacy metric, to adjudicate comparative asthmarelated safety risk.

\section{CONCLUSION}

$\beta$-agonist monotherapy may have a 'permissive' effect upon airway inflammation. Similar, consistent data are lacking for ICS-LABA combination therapy. This distinction explains the increased risk of serious asthma-related events with LABA monotherapy, whilst the available data supports the safety of ICS-LABA fixed combination therapy. Based on its own meta-analysis, however, the FDA reached somewhat different conclusions and has mandated a series of large, replicate studies to further evaluate the risk of serious asthma events with ICS-LABAs. This programme of studies contains certain inherent limitations which, it is hoped, the FDA will consider before data from these potentially landmark studies become available. Might these data additionally alter the FDA's 'lowest effective dose' philosophy and use of FEV1 as a de facto safety benchmark? Differences in regional pulmonary deposition pattern and pharmacology between different LABAs suggest potential limitations of the current regulatory approach. The use of models evaluating airway inflammation and bronchial reactivity which are more plausibly related to any putative increase in risk could offer an alternative approach with which to assess the relative safety risks and appropriate doses of novel LABAs.

\section{REFERENCES}

1. Speizer FE, Doll R, Heaf P. Observations on recent increase in mortality from asthma. Br Med J. 1968;1(5588):335-9.

2. Fraser P, Doll R. Geographical variations in the epidemic of asthma deaths. Br J Prev Soc Med. 1971;25(1):34-6.

3. Inman $\mathrm{WH}$, Adelstein AM. Rise and fall of asthma mortality in England and Wales in relation to use of pressurised aerosols. Lancet. 1969;2(7615):279-85.

4. Sears MR. The short- and long-term effects of $\beta 2$-agonists. In: Holgate ST, Austen KF, Lichtenstein LM, editors. Asthma: physiology, immunopharmacology, and treatment. London: Academic; 1993. p. 359-74.

5. Crane J, Pearce N, Flatt A, Burgess C, Jackson R, Kwong T, et al. Prescribed fenoterol and death from asthma in New Zealand, 198183: case-control study. Lancet. 1989;1(8644):917-22.

6. Pearce N, Grainger J, Atkinson M, Crane J, Burgess C, Culling $\mathrm{C}$, et al. Case-control study of prescribed fenoterol and death from asthma in New Zealand, 1977-81. Thorax. 1990;45:170-5.

7. Grainger J, Woodman K, Pearce N, et al. Prescribed fenoterol and death from asthma in New Zealand, 1981-7: a further casecontrol study. Thorax. 1991;46:105-11.

8. Spitzer WO, Suissa S, Ernst P, Horwitz RI, Habbick B, Cockcroft $\mathrm{D}$, et al. The use of beta-agonists and the risk of death and near death from asthma. N Engl J Med. 1992;326:501-6.

9. Aldridge RE, Hancox RJ, Taylor DR, Cowan JO, Winn MC, Frampton CM, et al. Effects of terbutaline and budesonide on sputum cells and bronchial hyperresponsiveness in asthma. Am J Respir Crit Care Med. 2000;161:1459-64.

10. Cockcroft DW, Swystun VA, Bhagat R. Interaction of inhaled beta 2 agonist and inhaled corticosteroid on airway responsiveness to allergen and methacholine. Am J Respir Crit Care Med. 1995;152(5 Pt 1):1485-9.

11. Cockcroft DW, O’Byrne PM, Swystun VA, Bhagat R. Regular use of inhaled albuterol and the allergen-induced late asthmatic response. J Allergy Clin Immunol. 1995;96:44-9.

12. Agarwal SK, Marshall Jr GD. Beta-adrenergic modulation of human type-1/type-2 cytokine balance. J Allergy Clin Immunol. 2000;105:91-8.

13. Panina-Bordignon P, Mazzeo D, Lucia PD, D’Ambrosio D, Lang R, Fabbri L, et al. Beta2-agonists prevent Th1 development by selective inhibition of interleukin 12. J Clin Investig. 1997;100:1513-9.

14. Taylor DR. The $\beta$-Agonist saga and its clinical relevance: on and on it goes. Am J Respir Crit Care Med. 2009;179:976-8.

15. Aziz I, Wilson AM, Lipworth BJ. Effects of once-daily formoterol and budesonide given alone or in combination on surrogate inflammatory markers in asthmatic adults. Chest. 2000;118(4):1049-58.

16. Kanniess F, Diamant Z, Lomax M, Jain M. Effects of low- vs high dose fluticasone/formoterol combination therapy on AMP challenge in asthmatic patients. Thorax. 2013;68:A150-1.

17. Nelson HS, Weiss ST, Bleecker ER, Yancey SW, Dorinsky PM, SMART Study Group. The salmeterol multicenter asthma research trial: a comparison of usual pharmacotherapy for asthma or usual pharmacotherapy plus salmeterol. Chest. 2006;129(1):15-26.

18. Levenson M. Long-acting beta-agonists and adverse asthma events meta-analysis statistical briefing package for joint meeting of the pulmonary-allergy drugs advisory committee, drug safety and risk management advisory committee and pediatric advisory committee on December 10-11, 2008. Quantitative safety and pharmacoepidemiology group, United States Food and Drug Administration. 2008.

19. AstraZeneca Briefing Materials. Review of the benefits and risks of formoterol-containing products. AstraZeneca. 2008

20. Chowdhury BA, Seymour SM, Levenson MS. Assessing the safety of adding LABAs to inhaled corticosteroids for treating asthma. N Engl J Med. 2011;364(26):2473-5.

21. ClinicalTrials.gov. A 6-month study to assess the safety and benefit of inhaled fluticasone propionate/salmeterol combination compared with inhaled fluticasone propionate in the treatment of adolescents and adults (12 Years of Age and Older) With 
Asthma. (AUSTRI). NCT01475721.https:/clinicaltrials.gov/ct2/ show/NCT01475721. Accessed 23 Jan 2015.

22. ClinicalTrials.gov. A 26 week, randomized, double-blind, parallel-group, active controlled, multicenter, multinational safety study evaluating the risk of serious asthma-related events during treatment with Symbicort ${ }^{\circledR}$, a fixed combination of inhaled corticosteroid (ICS) (Budesonide) and a long acting $\beta 2$-agonist (LABA) (Formoterol) as compared to treatment with ICS (Budesonide) alone in adult and adolescent ( $\geq 12$ Years of Age) patients with asthma. NCT01444430. https:// clinicaltrials.gov/ct2/show/NCT01444430. Accessed 23 Jan 2015.

23. A 26-week randomized, double-blinded, active controlled study comparing the safety of mometasone furoate/formoterol fumarate mdi fixed dose combination versus mometasone furoate MDI monotherapy in adolescents and adults with persistent asthma (Protocol No. P06241 Also Known as P202). NCT01471340. https://clinicaltrials.gov/ct2/show/NCT01471340. Accessed 23 Jan 2015.

24. ClinicalTrials.gov. A 26 week, randomized, active-controlled safety study of double-blind formoterol fumarate in free combination with an inhaled corticosteroid versus an inhaled corticosteroid in adolescent and adult patients with persistent asthma. NCT01845025. https://clinicaltrials.gov/ct2/show/ NCT01845025. Accessed 23 Jan 2015.

25. A 6-month safety and benefit study of inhaled fluticasone propionate/ salmeterol combination versus inhaled fluticasone propionate in the treatment of 6,200 pediatric subjects 4-11 years old with persistent asthma. (VESTRI). NCT01462344. https://clinicaltrials.gov/ct2/show/NCT01462344. Accessed 23 Jan 2015.

26. Suissa S, Ariel A. US Food and Drug Administration-mandated trials of long-acting $\beta$-agonists safety in asthma: will we know the answer? Chest. 2013;143(5):1208-13.

27. GlaxoSmithKline Sponsor Briefing Information. Benefit risk assessment of salmeterol for the treatment of asthma in adults and children. GlaxoSmithKline. 2008.
28. Mann M, Chowdhury B, Sullivan E, Nicklas R, Anthracite R, Meyer RJ. Serious asthma exacerbations in asthmatics treated with high-dose formoterol. Chest. 2003;124(1):70-4.

29. Center for Drug Evaluation and Research, US Food and Drug Administration. Application number 20-831, Medical Review. US Food and Drug Administration. 2001.

30. US Food and Drug Administration. Pulmonary allergy drugs advisory committee meeting FDA briefing document NDA 204275: fluticasone furoate and vilanterol inhalation powder for the long-term, maintenance treatment of airflow obstruction and for reducing exacerbations in patients with chronic obstructive pulmonary disease (COPD). US Food Drug Adm. 2013.

31. US Food and Drug Administration. Pulmonary-allergy drugs advisory committee meeting. NDA 022-383: indacaterol maleate (Arcapta ${ }^{\mathrm{TM}}$ Neohaler ${ }^{\mathrm{TM}}$ ) for the long-term once daily maintenance bronchodilator treatment of airflow obstruction in patients with chronic obstructive pulmonary disease (COPD), including chronic bronchitis and/or emphysema. US Food Drug Adm. 2011.

32. Wolfe J, Laforce C, Friedman B, Sokol W, Till D, Della Cioppa $\mathrm{G}$, et al. Formoterol, 24 microg bid, and serious asthma exacerbations: similar rates compared with formoterol, 12 microg bid, with and without extra doses taken on demand, and placebo. Chest. 2006;129(1):27-38.

33. Usmani OS, Biddiscombe MF, Barnes PJ. Regional lung deposition and bronchodilator response as a function of beta2agonist particle size. Am J Respir Crit Care Med. 2005;172(12):1497-504.

34. Cazzola M, Page CP, Calzetta L, Matera MG. Pharmacology and therapeutics of bronchodilators. Pharmacol Rev. 2012;64(3):450504 .

35. Battram C, Charlton SJ, Cuenoud B, Dowling MR, Fairhurst $\mathrm{RA}$, Farr $\mathrm{D}$, et al. In vitro and in vivo pharmacological characterization of 5-[(R)-2-(5,6-diethyl-indan-2-ylamino)-1-hydroxy-ethyl]-8-hydroxy-1H-quinolin-2-one (indacaterol), a novel inhaled beta(2) adrenoceptor agonist with a 24-h duration of action. J Pharmacol Exp Ther. 2006;317(2):762-70. 